\title{
Heat Transfer Enhancement of Copper-water Nanofluids in an Inclined Lid-driven Triangular Enclosure
}

\author{
M. M. Billah ${ }^{1 *}$, M. M. Rahman' ${ }^{2}$ M. Shahabuddin ${ }^{1}$, and A. K. Azad $^{3}$ \\ ${ }^{1}$ Department of Arts and Sciences, Ahsanullah University of Science and Tehcnology, \\ Dhaka-1208, Bangladesh \\ ${ }^{2}$ Department of Mathematics, Bangladesh University of Engineering and Technology, \\ Dhaka-1000, Bangladesh \\ ${ }^{3}$ Department of Business Administration, International Islamic University Chittagong, Dhaka, \\ Bangladesh
}

Received 17 May 2011, accepted in final revised form 14 August 2011

\begin{abstract}
A numerical study is conducted to investigate the transport mechanism of mixed convection in an inclined lid-driven triangular enclosure subject to cooling at the inclined right surface and simultaneous heating at the base surface filled with nanofluids. Fluid mechanics and conjugate heat transfer, described in terms of continuity, linear momentum and energy equations, are predicted by using the Galerkin finite element method. Numerical results are obtained for a wide range of parameters such as the Richardson number, tilt angle, and copper-water nanofluids is used with Prandtl number, $\operatorname{Pr}=6.2$. The streamlines, isotherm plots and the variation of the average Nusselt number at the hot surface as well as average fluid temperature in the enclosure is presented and discussed. It is found that the tilt angle strongly affects the fluid flow and heat transfer in the enclosure at the three convective regimes.
\end{abstract}

Keywords: Copper-water nanofluid; Penalty finite element method; Lid-driven triangular enclosure; Tilt angle; Mixed convection.

(C) 2011 JSR Publications. ISSN: 2070-0237 (Print); 2070-0245 (Online). All rights reserved.

doi:10.3329/jsr.v3i3.7642 J. Sci. Res. 3 (2), 525-538 (2011)

\section{Introduction}

The fluids that have been generally used for heat transfer applications, including water, mineral oils and ethylene glycol have a rather low thermal conductivity and do not meet the rising demand as an efficient heat transfer agent. In order to make up for the growing demands of modern technology such as chemical production, power stations and microelectronics, it is very important to develop new types of fluids that will be more

\footnotetext{
*Corresponding author:mmb.as@aust.edu; mmb.edu@gmail.com
} 
effective in terms of heat exchange performance. Such new types of fluids are nanofluids, which are new sort of heat transfer fluids containing a small quantity of nanosized particles that are uniformly and stably suspended in a liquid. These nanofluids have very high thermal conductivity. Researchers have started showing interest in heat transfer characteristics of these nanofluids in recent years.

The convective heat transfer feature of nanofluids is influenced by the thermophysical properties of the base fluid and nano particles. The function of a meticulous nanofluid for a heat transfer intention can be traditional by properly modeling the convective transportation in the nanofluid [1]. Khanafer et al. [2] presented a numerical model to find out natural convection heat transfer in nanofluids. The nanofluid in the enclosure was assumed to be in single phase. The authors investigated the effect of suspended nanoparticles on the buoyancy-driven heat transfer process and found that in any given Grashof number, heat transfer in the enclosure increased with the volumetric fraction of the copper nanoparticles in water. Jou and Tzeng [3] examined the heat transfer enhancement utilizing nanofluids in a two-dimensional enclosure for different pertinent parameters. Tiwari and Das [4] made a numerical investigation of heat transfer augmentation in a lid-driven square cavity filled with nanofluids. The authors found that both the Richardson number and the direction of the moving walls affect the fluid flow and heat transfer in the cavity. They concluded the variation of average Nusselt number is nonlinear with the solid volume fractions. A numerical studyis performed to analyze the transport mechanism of mixed convection in a lid-driven enclosure packed with nanofluids by Muthtamilselvan et al. [5]. Kim et al. [6] analytically investigated the instability in natural convection of nanofluids. Ghasemi and Aminossadati [7] studied mixed convection heat transfer in a lid-driven triangular enclosure filled with a water$\mathrm{Al}_{2} \mathrm{O}_{3}$ nanofluid. They found that the addition of $\mathrm{Al}_{2} \mathrm{O}_{3}$ nanoparticles enhances the heat transfer rate for different values of Richardson number and for each direction of the sliding wall motion. A parametric study on mixed convection flow in a lid-driven inclined square enclosure filled with water- $\mathrm{Al}_{2} \mathrm{O}_{3}$ nanofluid was performed by Nada and Chamkha [8]. Mansour et al. [9] conducted a numerical simulation on mixed convection flow in a square lid-driven cavity partially heated from below using nanofluid. Eastman et al. [10] considered pure copper nanoparticles of less than $10 \mathrm{~nm}$ sized and achieved $40 \%$ increase in thermal conductivity for only $0.3 \%$ volume fraction of the solid dispersed in ethylene glycol. The particle size effect and potential of nanofluids with smaller particles is presented in their results. Corcione [11] investigated theoretically the heat transfer features of buoyancy-driven nanofluids inside rectangular enclosures differentially heated at the vertical walls. An experimental investigation of flow and heat transfer characteristics for copper-water based nanofluids through a straight tube with a constant heat flux at the wall is conducted by Xuan and Li [12]. Their results demonstrate that the nanofluids give substantial enhancement of heat transfer rate compared to pure water. Saleh et al. [13] investigated heat transfer enhancement utilizing nanofluids in a trapezoidal enclosure for various pertinent parameters. Wang et al. [14] performed a nemerical investigation on the effective thermal conductivity 
enhancement of carbon fiber composites. Talebi et al. [15] numerically studied mixed convection flows in a square lid-driven cavity utilizing nanofluid. Tzeng et al. [16] investigated the effect of nanofluids when used as engine coolants. $\mathrm{CuO}$ and $\mathrm{Al}_{2} \mathrm{O}_{3}$ and antifoam were individually mixed with automatic transmission oil.

It is clear that the mixed convection heat transfer in enclosures using nanofluids has received great interest in recent years. But so far no study has been attempted to investigate the heat transfer characteristics of the nanofluids contained in an inclined liddriven triangular enclosure with different tilt angles. Hence, in this paper the effect of tilt angle in an inclined lid-driven triangular enclosure filled with $\mathrm{Cu}$-water nanofluid is investigated numerically.

\section{Mathematical Analysis}

We consider a steady two-dimensional flow of nanofluid contained in an inclined liddriven triangular enclosure as shown in Fig. 1. The length of the base wall and height of the sliding wall of the enclosure are denoted by $L$ and $H$, respectively. It is assumed that the sliding wall of the cavity is kept adiabatic and allowed to slide from bottom to top at a constant speed $V_{0}$. The temperature $\left(\theta_{h}\right)$ of the bottom wall is higher than the temperature $\left(\theta_{c}\right)$ of the right inclined wall. The free space in the enclosure is filled with copper water nanofluids. The present geometry is favored in mixed convection; using nanofluids could produce considerable enhancement of the heat transfer coefficients. The nanofluid in the enclosure is Newtonian, incompressible and laminar. The nanoparticles are assumed to have uniform shape and size. It is considered that thermal equilibrium exists between the base fluid and nanoparticles, and no slip occurs between the two media. The thermo-physical properties [15] of the nanofluid are listed in Table 1.

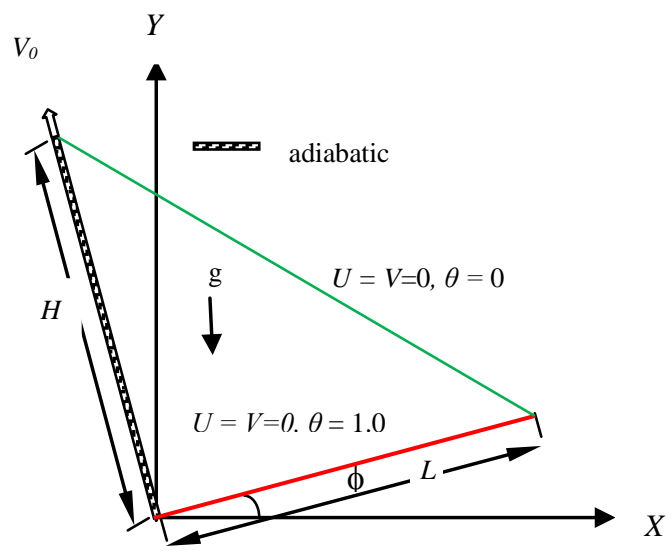

Fig. 1. Schematic of the problem with the domain and boundary conditions. 
Table 1. Thermophysical properties of water and copper [15].

\begin{tabular}{ccc}
\hline Property & water & copper \\
\hline$c_{p}$ & 4179 & 385 \\
$\rho$ & 997.1 & 8933 \\
$k$ & 0.613 & 401 \\
$\beta$ & $2.1 \times 10^{-4}$ & $1.67 \times 10^{-5}$ \\
\hline
\end{tabular}

The physical properties of the nanofluid are considered to be constant except the density variation in the body force term of the momentum equation which is satisfied by the Boussinesq's approximation. Under the above assumptions the governing equations. can be described as follows [5]:

$$
\begin{aligned}
& \frac{\partial u}{\partial x}+\frac{\partial v}{\partial y}=0 \\
& u \frac{\partial u}{\partial x}+v \frac{\partial u}{\partial y}=-\frac{1}{\rho_{n f}} \frac{\partial p}{\partial x}+\frac{\mu_{n f}}{\rho_{n f}}\left(\frac{\partial^{2} u}{\partial x^{2}}+\frac{\partial^{2} u}{\partial y^{2}}\right)+\frac{(\rho \beta)_{n f}}{\rho_{n f}}\left(T-T_{c}\right) g \sin \phi \\
& u \frac{\partial v}{\partial x}+v \frac{\partial v}{\partial y}=-\frac{1}{\rho_{n f}} \frac{\partial p}{\partial y}+\frac{\mu_{n f}}{\rho_{n f}}\left(\frac{\partial^{2} v}{\partial x^{2}}+\frac{\partial^{2} v}{\partial y^{2}}\right)+\frac{(\rho \beta)_{n f}}{\rho_{n f}}\left(T-T_{c}\right) g \cos \phi \\
& u \frac{\partial T}{\partial x}+v \frac{\partial T}{\partial y}=\alpha_{n f}\left(\frac{\partial^{2} T}{\partial x^{2}}+\frac{\partial^{2} T}{\partial y^{2}}\right)
\end{aligned}
$$

The effective density $\rho_{n f}$ of the nanofluid is defined by

$$
\rho_{n f}=(1-\delta) \rho_{f}+\delta \rho_{s}
$$

where $\delta$ is the solid volume fraction of nanoparticles. In addition, the thermal diffusivity $\alpha_{n f}$ of the nano fluid can be expressed as:

$$
\alpha_{n f}=\frac{k_{n f}}{\left(\rho c_{p}\right)_{n f}}
$$

The heat capacitance of nanofluids can be defined as:

$$
\left(\rho c_{p}\right)_{n f}=(1-\delta)\left(\rho c_{p}\right)_{f}+\delta\left(\rho c_{p}\right)_{s}
$$

Additionally, $(\rho \beta)_{n f}$ is the thermal expansion coefficient of the nanofluid and it can be determined by

$$
(\rho \beta)_{n f}=(1-\delta)(\rho \beta)_{f}+\delta(\rho \beta)_{s}
$$


Furthermore, $\mu_{n f}$ is the dynamic viscosity of the nanofluid introduced by Brikman [17] as

$$
\mu_{n f}=\frac{\mu_{f}}{(1-\delta)^{2.5}}
$$

The effective thermal conductivity of nanofluid was intoduced by Kanafer et al. [2] as:

$$
\frac{k_{n f}}{k_{f}}=\frac{k_{s}+2 k_{f}-2 \delta\left(k_{f}-k_{s}\right)}{k_{s}+2 k_{f}+\delta\left(k_{f}-k_{s}\right)}
$$

where, $k_{s}$ is the thermal conductivity of the nanoparticles and $k_{f}$ is the thermal conductivity of base fluid.

Introducing the following dimensionless variables

$$
X=\frac{x}{L}, Y=\frac{y}{L}, U=\frac{u}{V_{0}}, V=\frac{v}{V_{0}}, P=\frac{(p+\rho g y) L^{2}}{\rho_{n f} V_{0}^{2}}, \theta=\frac{\left(T-T_{C}\right)}{\left(T_{h}-T_{C}\right)}
$$

the governing equations may be written in the dimensionless form as

$$
\begin{aligned}
& \frac{\partial U}{\partial X}+\frac{\partial V}{\partial Y}=0 \\
& U \frac{\partial U}{\partial X}+V \frac{\partial U}{\partial Y}=-\frac{\partial P}{\partial X}+\frac{1}{R e} \frac{\rho_{f}}{\rho_{n f}} \frac{1}{(1-\delta)^{2.5}}\left(\frac{\partial^{2} U}{\partial X^{2}}+\frac{\partial^{2} U}{\partial Y^{2}}\right)+\frac{(\rho \beta)_{n f}}{\rho_{n f} \beta_{f}} R i \theta \sin \phi \\
& U \frac{\partial V}{\partial X}+V \frac{\partial V}{\partial Y}=-\frac{\partial P}{\partial Y}+\frac{1}{R e} \frac{\rho_{f}}{\rho_{n f}} \frac{1}{(1-\delta)^{2.5}}\left(\frac{\partial^{2} V}{\partial X^{2}}+\frac{\partial^{2} V}{\partial Y^{2}}\right)+\frac{(\rho \beta)_{n f}}{\rho_{n f} \beta_{f}} R i \theta \cos \phi \\
& U \frac{\partial \theta}{\partial X}+V \frac{\partial \theta}{\partial Y}=\frac{\alpha_{n f}}{\alpha_{f}} \frac{1}{\operatorname{RePr}\left(\frac{\partial^{2} \theta}{\partial X^{2}}+\frac{\partial^{2} \theta}{\partial Y^{2}}\right)}
\end{aligned}
$$

The nondimensional numbers that appear in Eqs. (13)-(15) are as follows:

Reynolds number $R e=V_{0} L / v_{f}$, Prandtl number $\operatorname{Pr}=v_{f} / \alpha_{f}$ and Richardson number $R i=g \beta_{f}\left(T_{h}-T_{C}\right) L / V_{0}^{2}$

The appropriate boundary conditions for the governing equations are:

On the bottom wall: $U=V=0, \theta=1$

On the left inclined wall: $U=0, V=1, \frac{\partial \theta}{\partial N}=0$

On the right inclined wall: $U=V=0, \theta=0$ where $N$ is the non-dimensional distances either $X$ or $Y$ direction acting normal to the surface. 
The average Nusselt number at the heated surface of the cavity may be expressed as

$$
N u_{a v}=-\frac{k_{n f}}{k_{f}} \int_{0}^{1} \frac{\partial \theta}{\partial Y} d X
$$

and average fluid temperature in the enclosure is defined by

$$
\theta_{a v}=\int \theta d \bar{V} / \bar{V}
$$

where $\bar{V}$ is the cavity volume.

The fluid motion is displayed using the stream function $\psi$ obtained from velocity components $U$ and $V$. The relationships between stream function and velocity components [18] for two dimensional flows are

$$
U=\frac{\partial \psi}{\partial Y}, V=-\frac{\partial \psi}{\partial X}
$$

\section{Numerical Solution}

\subsection{Method of solution}

In this section, the Galerkin finite element method is discussed to solve the nondimensional governing equations along with boundary conditions for the considered problem. The equation of continuity has been used as a constraint due to mass conservation and this restriction may be used to find the pressure distribution. The penalty finite element method [19] is used to solve the Eqs. (13) - (15), where the pressure $P$ is eliminated by a penalty constraint $\gamma$, and the incompressibility criteria given by Eq. (12) which can be expressed as:

$$
P=-\gamma\left(\frac{\partial U}{\partial X}+\frac{\partial V}{\partial Y}\right)
$$

The continuity equation is automatically fulfilled for large values of $\gamma$.

The momentum equations (Eqs. (13) and (14)) reduce to

$$
\begin{aligned}
& U \frac{\partial U}{\partial X}+V \frac{\partial U}{\partial Y}=\gamma \frac{\partial}{\partial X}\left(\frac{\partial U}{\partial X}+\frac{\partial V}{\partial Y}\right)+\frac{1}{R e} \frac{\rho_{f}}{\rho_{n f}} \frac{1}{(1-\delta)^{2.5}}\left(\frac{\partial^{2} U}{\partial X^{2}}+\frac{\partial^{2} U}{\partial Y^{2}}\right)+\frac{(\rho \beta)_{n f}}{\rho_{n f} \beta_{f}} \operatorname{Ri} \theta \sin \phi \\
& U \frac{\partial V}{\partial X}+V \frac{\partial V}{\partial Y}=\gamma \frac{\partial}{\partial Y}\left(\frac{\partial U}{\partial X}+\frac{\partial V}{\partial Y}\right)+\frac{1}{R e} \frac{\rho_{f}}{\rho_{n f}} \frac{1}{(1-\delta)^{2.5}}\left(\frac{\partial^{2} V}{\partial X^{2}}+\frac{\partial^{2} V}{\partial Y^{2}}\right)+\frac{(\rho \beta)_{n f}}{\rho_{n f} \beta_{f}} \operatorname{Ri} \theta \cos \phi
\end{aligned}
$$

Expanding the velocity components $(U, V)$, and temperature $(\theta)$ using basis set $\left\{\Phi_{k}\right\}_{k=1}^{N}$ as 


$$
U \approx \sum_{k=1}^{N} U_{k} \Phi_{k}(X, Y), V \approx \sum_{k=1}^{N} V_{k} \Phi_{k}(X, Y), a n \theta l \approx \sum_{k=1}^{N} \theta_{k} \Phi_{k}(X, Y)
$$

Then the Galerkin finite element technique yields the subsequent nonlinear residual equations for the Eqs. (15), (20) and (21) respectively at nodes of the internal domain $\Omega$ :

$$
\begin{aligned}
& R_{i}^{(1)}=\sum_{k=1}^{N} \theta_{k} \int\left[\int_{\Omega}\left[\sum_{k=1}^{N} U_{k} \Phi_{k}\right) \frac{\partial \Phi_{k}}{\partial X}+\left(\sum_{k=1}^{N} V_{k} \Phi_{k}\right) \frac{\partial \Phi_{k}}{\partial Y}\right] \Phi_{i} d X d Y \\
& -\frac{\alpha_{n f}}{\alpha_{f} \operatorname{Re} P r} \sum_{k=1}^{N} \theta_{k} \int\left[\frac{\partial \Phi_{i}}{\partial X} \frac{\partial \Phi_{k}}{\partial X}+\frac{\partial \Phi_{i}}{\partial Y} \frac{\partial \Phi_{k}}{\partial Y}\right] d X d Y \\
& R_{i}^{(2)}=\sum_{k=1}^{N} U_{k} \int\left[\int_{\Omega}\left[\left(\sum_{k=1}^{N} U_{k} \Phi_{k}\right) \frac{\partial \Phi_{k}}{\partial X}+\left(\sum_{k=1}^{N} V_{k} \Phi_{k}\right) \frac{\partial \Phi_{k}}{\partial Y}\right] \Phi_{i} d X d Y\right. \\
& -\gamma\left[\sum_{k=1}^{N} U_{k} \int_{\Omega} \frac{\partial \Phi_{i}}{\partial X} \frac{\partial \Phi_{k}}{\partial X} d X d Y+\sum_{k=1}^{N} V_{k} \int_{\Omega} \frac{\partial \Phi_{i}}{\partial X} \frac{\partial \Phi_{k}}{\partial Y} d X d Y\right]-\frac{1}{R e} \frac{\rho_{f}}{\rho_{n f}} \frac{1}{(1-\delta)^{2.5}} \\
& \sum_{k=1}^{N} U_{k} \int_{\Omega}\left[\frac{\partial \Phi_{i}}{\partial X} \frac{\partial \Phi_{k}}{\partial X}+\frac{\partial \Phi_{i}}{\partial Y} \frac{\partial \Phi_{k}}{\partial Y}\right] d X d Y-\frac{(\rho \beta)_{n f}}{\rho_{n f} \beta_{f}} R i \sin \phi \int_{\Omega}\left(\sum_{k=1}^{N} \theta_{k} \Phi_{k}\right) \Phi_{i} d X d Y \\
& R_{i}^{(3)}=\sum_{k=1}^{N} V_{k} \int\left[\left(\sum_{\Omega=1}^{N} U_{k} \Phi_{k}\right) \frac{\partial \Phi_{k}}{\partial X}+\left(\sum_{k=1}^{N} V_{k} \Phi_{k}\right) \frac{\partial \Phi_{k}}{\partial Y}\right] \Phi_{i} d X d Y- \\
& \gamma\left[\sum_{k=1}^{N} U_{k} \int_{\Omega} \frac{\partial \Phi_{i}}{\partial Y} \frac{\partial \Phi_{k}}{\partial X} d X d Y+\sum_{k=1}^{N} V_{k} \int_{\Omega} \frac{\partial \Phi_{i}}{\partial Y} \frac{\partial \Phi_{k}}{\partial Y} d X d Y\right] \\
& -\frac{1}{R e} \frac{\rho_{f}}{\rho_{n f}} \frac{1}{(1-\delta)^{2.5}} \sum_{k=1}^{N} V_{k}\left[\frac{\partial \Phi_{i}}{\partial X} \frac{\partial \Phi_{k}}{\partial X}+\frac{\partial \Phi_{i}}{\partial Y} \frac{\partial \Phi_{k}}{\partial Y}\right] d X d Y-\frac{(\rho \beta)_{n f}}{\rho_{n f} \beta_{f}} \operatorname{Ri} \cos \phi \int_{\Omega}\left(\sum_{k=1}^{N} \theta_{k} \Phi_{k}\right) \Phi_{i} d X d Y
\end{aligned}
$$

Three points Gaussian quadrature is used to evaluate the integrals in the residual equations. The non-linear residual equations (Eqs. (23) - (25)) are solved using NewtonRaphson method to determine the coefficients of the expansions in Eq. (22). The convergence of solutions is assumed when the relative error for each variable between consecutive iterations is recorded below the convergence criterion $\varepsilon$ such that $\left|\Psi^{n+1}-\Psi^{n}\right| \leq 10^{-4}$, where $n$ is the number of iteration and $\Psi$ is a function of $U, V$, and $\theta$.

\subsection{Grid independence study}

In order to obtain grid independent solution, a grid refinement study has been performed for $R e=100, R i=5.0, \phi=60$ and $\delta=0.04$ in an inclined lid-driven triangular enclosure. In the present work, we examine five different non-uniform grid systems with the following number of elements within the resolution field: 1486, 2808, 3490, 4894 and 5588. The numerical scheme is carried out for highly precise key in the average Nusselt $N u_{a v}$ number for the aforesaid elements to develop an understanding of the grid fineness 
as shown in Fig. 2. The scale of average Nusselt number $\left(N u_{a v}\right)$ for 4894 elements shows a little difference with the results obtained for the other elements. Hence considering the non-uniform grid system of 4894 elements is preferred for the computation of all cases.

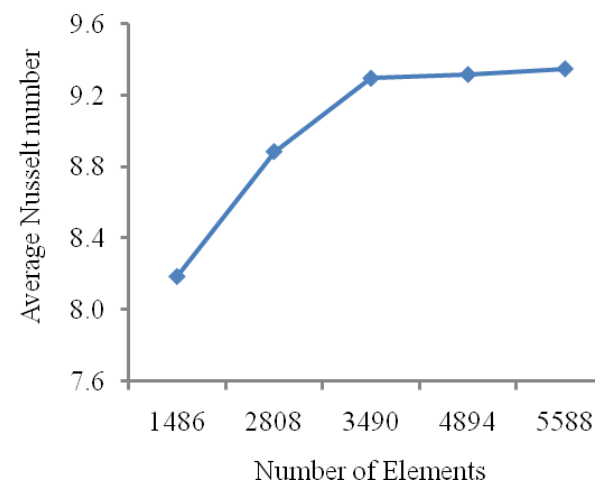

Fig. 2. Grid independency study for $R e=100, R i=5.0, \phi=60$ and $\delta=0.04$.

\subsection{Code validation}

The model validation is an essential part of a numerical investigation. The computational model is validated against the problem of mixed convection in a lid-driven enclosure filled with nanofluids [5]. The cavity was heated at the top wall and cooled at the bottom side while the rest of the boundaries were insulated. The comparison of the average Nusselt number (at the hot surface) between the result of the present code and the results found in the literature [5] for different solid volume fractions are documented in Table 2. The comparisons reveal an excellent agreement with the reported studies. This validation boosts the confidence in the numerical outcome of the present study.

Table 2. Comparison of $\mathrm{Nu}$ with those of Muthtamilselvan et al. [5]

\begin{tabular}{crcc}
\hline \multirow{2}{*}{$\delta$} & \multicolumn{3}{c}{$N u$} \\
\cline { 2 - 4 } & Ref. [5] & Present study & \% increase \\
\hline 0.0 & 2.26 & 2.43 & 7.52 \\
0.02 & 2.40 & 2.60 & 8.33 \\
0.04 & 2.56 & 2.77 & 8.20 \\
0.06 & 2.73 & 2.96 & 8.42 \\
0.08 & 2.91 & 3.17 & 8.93 \\
\hline
\end{tabular}




\section{Results and Discussion}

The present numerical study is carried out for copper-water as working fluid with Prandtl number of 6.2. Our effort is to investigate the effects of controlling parameters namely the tilt angle $(\phi)$, and Richardson number (Ri). The effect of the tilt angle is investigated in the range of $0-60$ while $R e$ and solid volume fraction $\delta$ are kept fixing at 100 and 0.04 , respectively. It is worth noting that the value of $R i$ is varied from 0.1 to 5 to cover forced convection dominated region, pure mixed convection and free convection dominated region. Moreover, the results of this study are presented in terms of streamlines and isotherms. Furthermore, the heat transfer effectiveness of the enclosure is displayed in terms of average Nusselt number $\mathrm{Nu}$ and the dimensionless average bulk temperature $\theta_{\mathrm{av}}$.

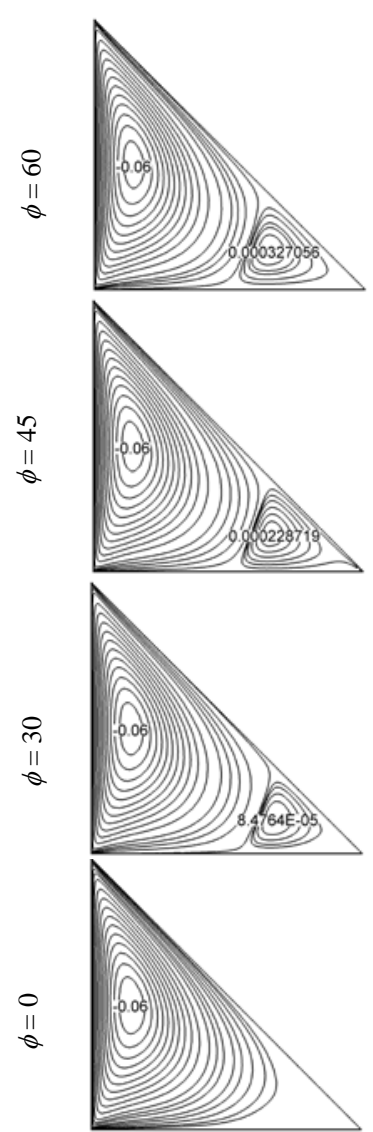

(a)

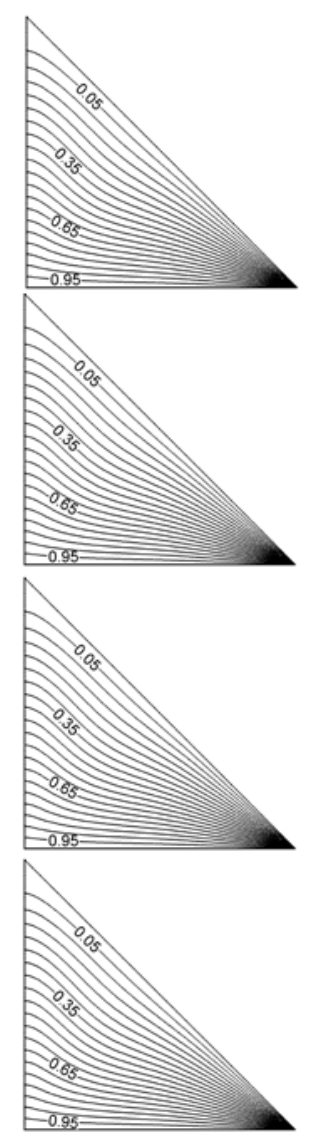

(b)

Fig. 3. (a) Streamlines and (b) Isotherms for different values of tilt angle $\phi$ and Richardson number $R i=0.1$. 
Fig. 3 shows the streamlines and isotherms in an inclined lid-driven triangular enclosure for four tilt angles $\phi(=0,30,45$ and 60$)$ at $R i=0.1$. The fluid flow in a 2-D lid-driven cavity is characterized by a primary circulating cell near the vicinity of the sliding wall in the enclosure generated by the lid and a weaker anticlockwise rotating cell near the right bottom corner for the higher values of $\phi(=30,45$ and 60$)$. It is can easily be seen from the left column of Fig. 3, the streamlines collapse together at the right base corner while tilit angle is zero. In addition, the main cell is generated by the lid dragging the neighboring fluid. Though the flow strength of the main cell is same, the size of the main cell is affected for all values of $\phi$. It is also found from the streamlines that the size of anticlockwise rotating cell is decreasing when $\phi$ is decreased to 30 , and dramatically this cell disappears when $\phi=0$. This is due to a decrease in the tilt angle as a result of high-energy transport through the flow associated with the irregular motion of the ultrafine particles. The isotherm plots indicate the lines with equal intervals between unity (hot wall) and zero (cold wall). It is noticed that isotherm lines become denser towards the hot surface for each value of $\phi$ at the considered value of $R i=0.1$.
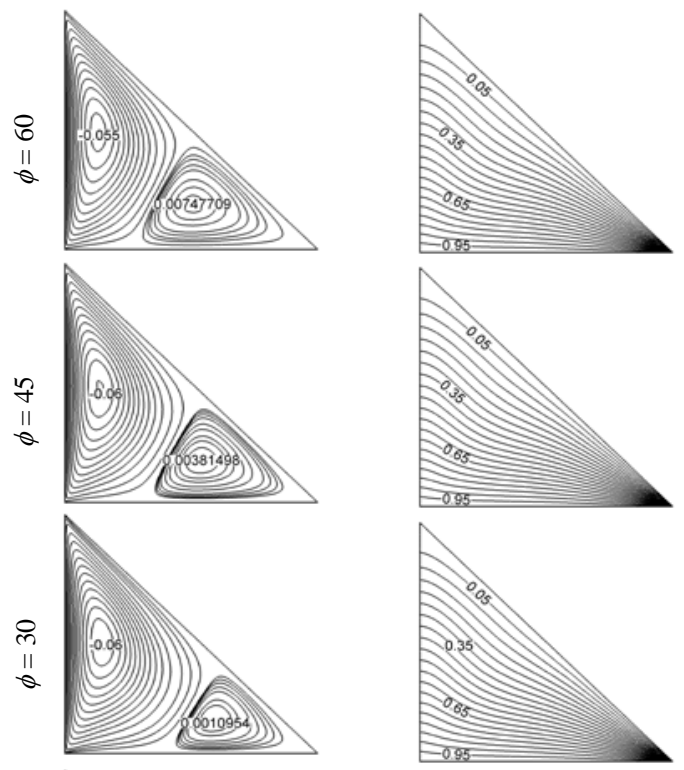

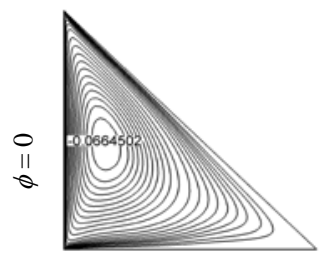

(a)

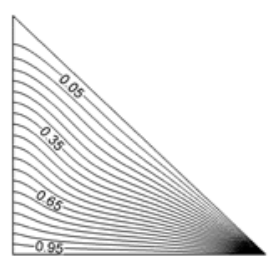

(b)

Fig. 4. (a) Streamlines and (b) Isotherms for different values of tilt angle $\phi$ and Richardson number $R i=1.0$. 
The effect of various tilt angles on the flow and thermal field at $R i=1.0$ is displayed in Fig. 4. A clockwise rotating major cell is observed near the sliding wall of the enclosure for all of $\phi$ but a counter clockwaise-minor cell is seen at the lower right foot corner of the enclosure for higher values of $\phi$. The size of the small cell decreases with a decrease in $\phi$ and diminish while $\phi=0$. While the flow pattern at $R i=1.0$ is compared with that of at $R i=0.1$ as shown in Fig. 3, it is observed that the minor cell is bigger in size at $R i=1.0$ indicating the flow pattern strongly affected in the mixed convection regime. Fig. 4 indicates that mixed convection is the dominating mode in the triangular enclosure. In this case, the isotherms become denser gradually towards the hot base surface of the enclosure for the increasing value of $\phi$, which indicates the steeper temperature gradient in the horizontal direction in this region. At the upper part of the cavity, the temperature gradients are very small due to the mechanically-driven circulations.
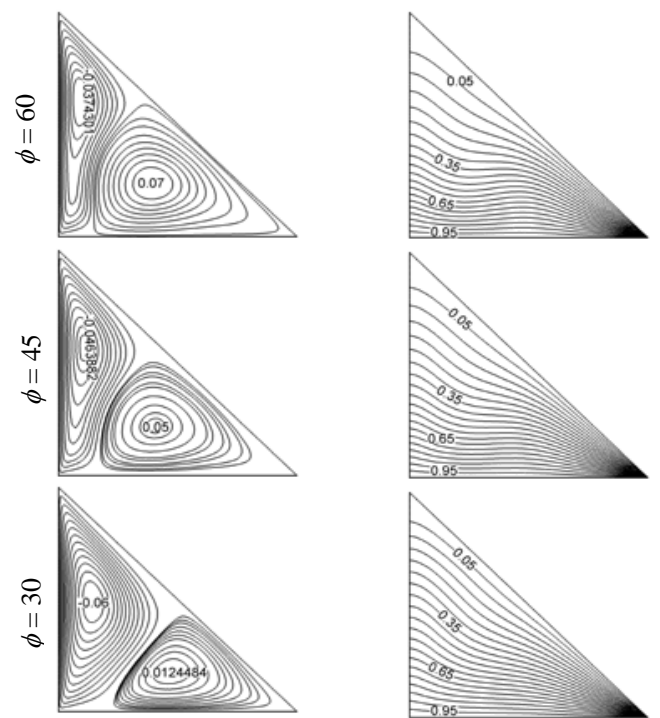

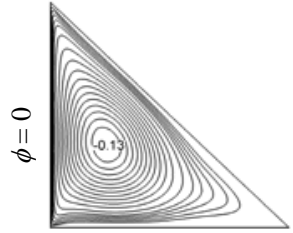

(a)

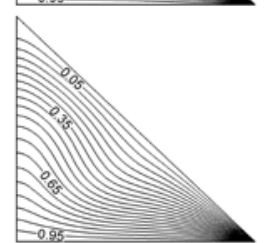

(b)

Fig. 5. (a) Streamlines and (b) Isotherms for different values of tilt angle $\phi$ and Richardson number $R i=5.0$.

Fig. 5 illustrates the effect for considered values of $\phi$ on streamlines and isotherms at $R i=5.0$. In this case, the clockwise rotating main cell decreases rapidly with the 
increasing tilt angles. As a result the anti clockwise eddy increases very quickly for the higher values of $\phi$. It is observed that the anti clockwise vortex dominates the main cell. It is evident to the shape change of the core main vortices. As the value of $\phi$ increases the core vortices expand vertically. It indicates the reduction of the flow strength of this eddy, which occurs due to the movement of the lid. Comparing Figs. 3 to 5, the thicken thermal layer is observed near the vicinity of the base surface when $\mathrm{Ri}=5.0$. This thicken thermal layer is reduced when the Richerdson number Ri decreases.

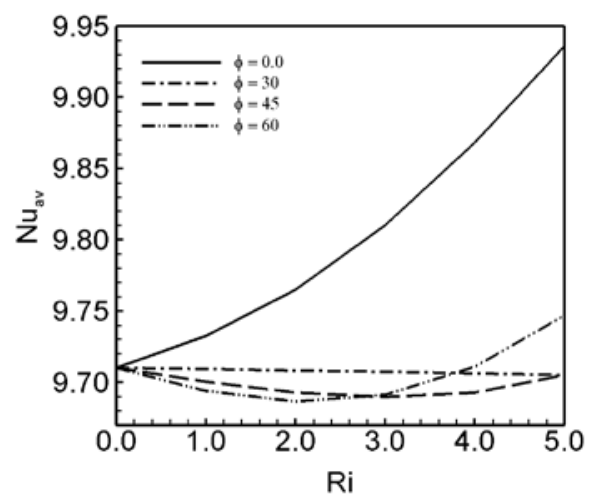

Fig. 6. Effect of tilt angle $\phi$ on average Nusselt number at the heated surface in the cavity, while $\delta=0.04$.

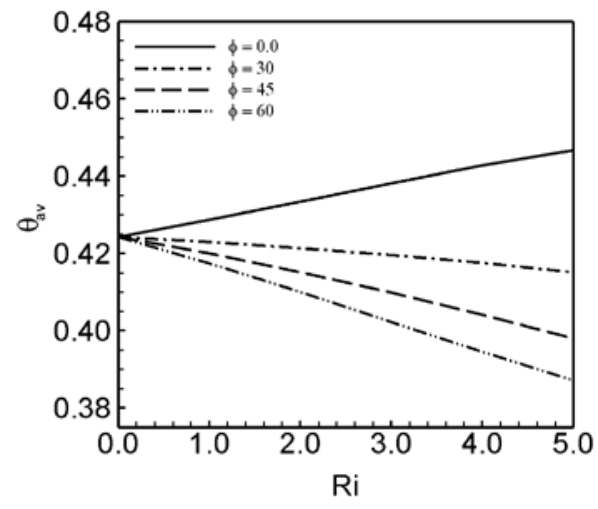

Fig. 7. Effect of tilt angle $\phi$ on average fluid temperature in the cavity, while $\delta=$ 0.04 .

Fig. 6 plots the average Nusselt number $\left(N u_{a v}\right)$ at the hot surface, which is a measure of the overall heat transfer rate as a function of Richardson number for the abovementioned values of tilt angle. It is clearly seen that $N u_{a v}$ increases very swiftly when the value of $\phi$ is zero and mildly for the higher values of $\phi(=45$ and 60$)$ with the increasing $R i$. But $N u_{a v}$ decreases slightly with the increasing $R i$ for $\phi=30$. However, the values of $N u_{a v}$ are always peak for the lowest value of $\phi(=0)$. The effect of cavity inclination on average fluid temperature $\left(\theta_{a v}\right)$ in the enclosure is exposed in Fig. 8. It is observed that $\theta_{a v}$ decreases significtly with the increasing $R i$ for the higher values of $\phi(=$ 30,45 and 60). But an opposite behaviour is observed for the lowest value of $\phi(=0)$. For this reason of $\theta_{a v}$ is maximum for the smallest values of $\phi(=0)$.

\section{Conclusion}

Mixed convection flow and heat transfer enhancement in an inclined lid-driven triangular enclosure filled with nanofluids is studied numerically. The flow and heat transport structures are presented in terms of streamlines and isotherms, respectively. 
Results for the different parametric situation such as the tilt angle $(\phi)$ and Richardson number $(R i)$ are presented and discussed.

In view of the obtained results, following findings may be summarized:

a. The inclination angle has more significant effect on the flow field than thermal field.

b. The flow and thermal fields as well as the heat transfer rate inside the enclosure are strongly dependent on the Richardson number.

c. Nanofluids are capable to modify the flow pattern.

d. The inclination angle is a good control parameter for both pure and nanofluid filled enclosures.

\section{Nomenclatures}

$c_{p} \quad$ Specific heat at constant pressure

$g$ gravitational acceleration $\left(\mathrm{ms}^{-2}\right)$

$H$ enclosure height (m)

$k \quad$ thermal conductivity $\left(\mathrm{Wm}^{-1} \mathrm{~K}^{-1}\right)$

$L \quad$ length of the cavity (m)

$\mathrm{Nu} \quad$ Nusselt number

$p \quad$ dimensional pressure $\left(\mathrm{Nm}^{-2}\right)$

$P \quad$ dimensionless pressure

Pr Prandtl number

Re Reynolds number

Ri Richardson number

$T$ temperature $(\mathrm{K})$

$u \quad$ horizontal velocity component $\left(\mathrm{ms}^{-1}\right)$

$U$ dimensionless horizontal velocity component

$v \quad$ vertical velocity component $\left(\mathrm{ms}^{-1}\right)$

$V$ dimensionless vertical velocity component

$V_{0} \quad$ lid velocity $\left(\mathrm{ms}^{-1}\right)$

$\bar{V} \quad$ cavity volume $\left(\mathrm{m}^{3}\right)$

$x \quad$ horizontal coordinate (m)

$X \quad$ dimensionless horizontal coordinate

$\begin{array}{ll}y & \text { vertical coordínate }(\mathrm{m}) \\ Y & \text { dimensionless vertical coordinate } \\ \text { Greek symbols } & \\ \alpha & \text { thermal diffusivity }\left(\mathrm{m}^{2} \mathrm{~s}^{-1}\right) \\ \beta & \text { thermal expansion coefficient }\left(\mathrm{K}^{-1}\right) \\ \delta & \text { solid volume fraction } \\ \mu & \text { dynamic viscosity }\left(\mathrm{kg} \mathrm{m}^{-1} \mathrm{~s}^{-1}\right) \\ v & \text { kinematic viscosity }\left(\mathrm{m}^{2} \mathrm{~s}^{-1}\right) \\ \theta & \text { non-dimensional temperature } \\ \rho & \text { density }\left(\mathrm{kg} \mathrm{m} \mathrm{m}^{-3}\right) \\ \psi & \text { streamfunction } \\ \phi & \text { tilt angle, degree }\left({ }^{0}\right) \\ \gamma & \text { penalty parameter } \\ \text { Subscripts } & \\ \text { av } & \text { average } \\ h & \text { hot } \\ c & \text { cold } \\ \mathrm{f} & \text { fluid } \\ \mathrm{nf} & \text { nanofluid } \\ \mathrm{s} & \text { Solid nanoparticle }\end{array}$

\section{References}

1. S. Kumar, S. K. Prasad, and J. Banerjee, Appl. Math. Model 34, 573 (2010). http://dx.doi.org/10.1016/j.apm.2009.06.026

2. K. Khanafer, K. Vafai, and M. Lightstone, Int. J. of Heat and Mass Transfer 46, 3639 (2003). http://dx.doi.org/10.1016/S0017-9310(03)00156-X

3. R.Y. Jou, and S.C. Tzeng, Int. Comm. Heat Mass Transfer 33, 727 (2006). http://dx.doi.org/10.1016/j.icheatmasstransfer.2006.02.016

4. R.K. Tiwari, and M.K. Das, Int. J. of Heat and Mass Transfer 50, 2002 (2007). http://dx.doi.org/10.1016/j.ijheatmasstransfer.2006.09.034

5. M. Muthtamilselvan, P. Kandaswamy, and J. Lee, Commun Nonlinear Sci Numer Simulat 15, 1501 (2010). http://dx.doi.org/10.1016/j.cnsns.2009.06.015

6. J. Kim, Y. T. Kang, and C. K. Choi, Phys Fluids 16, 2395 (2004). http://dx.doi.org/10.1063/1.1739247

7. B. Ghasemi, and S. M. Aminossadati, Int. Commun. Heat Mass Transfer 37, 1142 (2010). 
http://dx.doi.org/10.1016/j.icheatmasstransfer.2010.06.020

8. E. A. Nada, and A. J. Chamkha, European J. Mechanics B/Fluids 29, 472 (2010).

9. M. A. Mansour, R. A. Mohamed, M. M. Abd-Elaziz, S. E. Ahmed, Int. Commun. Heat Mass Transfer 37, 1504 (2010). http://dx.doi.org/10.1016/j.icheatmasstransfer.2010.09.004

10. J. A. Eastman, SUS. Choi, S. Li, W. Yu, and L. J. Thompson, Appl Phys Lett 78, 718 (2001). http://dx.doi.org/10.1063/1.1341218

11. M. Corcione, Int. J. Thermal Sciences 49, 1536 (2010). http://dx.doi.org/10.1016/j.ijthermalsci.2010.05.005

12. Y. Xuan, and Q. Li, ASME J. Heat Transfer 125, 151 (2003). http://dx.doi.org/10.1115/1.1532008

13. H. Saleh, R. Roslan, and I. Hashim, Int. J. Heat Mass Transfer 54, 194 (2011). http://dx.doi.org/10.1016/j.ijheatmasstransfer.2010.09.053

14. M. Wang, Q. Kang, and P. Ning, Appl Therm Eng 29, 418 (2009). http://dx.doi.org/10.1016/j.applthermaleng.2008.03.004

15. F. Talebi, A. H. Mahmoudi, and M. Shahi, Int. Commun. Heat Mass Transfer 37, 79 (2010). http://dx.doi.org/10.1016/j.icheatmasstransfer.2009.08.013

16. S. C. Tzeng, C. W. Lin, and K. D. Huang, Acta Mech. 179, 11 (2005). http://dx.doi.org/10.1007/s00707-005-0248-9

17. H. C. Brinkman, J. Chem. Phys. 20, 571 (1952). http://dx.doi.org/10.1063/1.1700493

18. G. K. Batchelor, An Introduction to Fluid Dynamics (Cambridge University Press, London, 1993).

19. T. Basak, S. Roy, S. K. Babu, and A. R. Balakrishnan, Int. J. Heat Mass Transfer 51, 4496 (2008). http://dx.doi.org/10.1016/j.ijheatmasstransfer.2007.12.01 